\title{
PENGARUH PELATIHAN MOTIVASI DAN KOMPENSASI TERHADAP KINERJA KARYAWAN BAGIAN SPINING 2 PT. SARI WARNA ASLI II BOYOLALI
}

\author{
Latif Budi Pramono ${ }^{1)}$, Unna Ria Safitri ${ }^{2}$, Hari Purwanto ${ }^{3)}$ \\ ${ }^{1)}$ Program Studi Manajemen Fakultas Ekonomi Universitas Boyolali \\ J1. Pandanaran 405, Telp. 0276321328 Boyolali \\ ${ }^{2)}$ Fakultas Ekonomi Universitas Boyolali \\ Jl. Pandanaran 405, Telp. 0276321328 Boyolali \\ ${ }^{3)}$ Fakultas Ekonomi Universitas Boyolali \\ Jl. Pandanaran 405, Telp. 0276321328 Boyolali

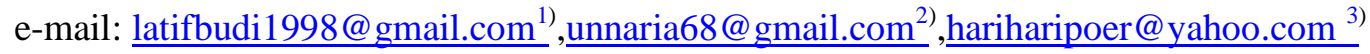

\begin{abstract}
ABSTRAK
Di era globalisasi seperti sekarang hampir seluruh perusahan di tuntut untuk menambah kemampuan sumber daya manusianya agar tujuan perusahaan dapat tercapai. Maka penulis melakukan penelitian yang berhubungan dengan kinerja karyawan. Bagian Spining 2 PT. Sari Warna Asli II Boyolali merupakan departemen baru. Esensi dari penelitian ini iyalah agar dapat mengukur dan bisa mengetahui tingkat kerja karyawan pada konsep pelatihan, motivasii serta kompensasi pada kerja spinning 2 PT Sari Warna Asli II Boyolali.

Pada penelitian yang di lakukan metode yang di gunakan iyalah metode kuantitatif. Cara pengambilan data melalui kuesioner dan stadi dokumen. Dengan populasi 635 karyawan, sampel pada data ini adalah 250 responden karyawan bagian Spining 2 PT. Sari Warna Asli II Boyolali. Teknik penyelidikan data yang dipakaiyaitu regresi linear berganda dengan menggunakan SPSS 22.

Hasil riset ini dapat ditarik kesimpulan bahwa pelatihan,motivasi, dan kompensasi berpengaruh positif dan signifikan
\end{abstract}

Kata kunci : kinerja karyawan, pelatihan, motivasi, kompensasi

\begin{abstract}
In this era of globalization, almost all companies are required to increase the capacity of their human resources so that company goals can be achieved. So the authors conducted research related to employee performance. Spining Section 2 PT. Sari Warna Asli II Boyolali is a new department. The essence of this research is to be able to measure and be able to know the work level of employees on the concept of training, motivation and compensation at spinning 2 work at PT Sari Warna Asli II Boyolali.

In research, the method used is the quantitative method. How to collect data through questionnaires and document stadi. With a population of 635 employees, the sample in this data is 250 respondents employees of the Spining 2 PT. Sari Warna Asli II, Boyolali. The data investigation technique used is multiple linear regression using SPSS 22.

The result of this researc can be concluded thats training, motivation, and compensation have a positive and significant effect simultaneously and partially on employee productivity..

Keywords: employee performance, training, motivation, compensation
\end{abstract}




\section{Pendahuluan}

\section{Latar belakang masalah}

Menurut Malthis \& Jackson, (2002) pelatihan merupakan suatu cara atau metoe di mana semua orang akan mencari kecakapan agar kemudian bisa dapat membantu pecapaian atau tujuan dari organisasi maupun perusahaan. Training jugadapat di definisikan sebuah langakah agar seseorang maupun lebih agar menjadi searah agar dapat satu tujuan di dalam perusahaan atau organisasi. Dengan penjelasan di atas maka jika semua bisa di lakukan tidak menuntut kemungkinan bisa berimpekkepada kinerja karyawan yang bisa diharapkan semakin bagus pula. Sebaliknya tidak hanya dalam bentuk pelatian sebagai penunjang kinerja karyawan tetapi motivasi juga mempunyai peranan yang amat penting. Motivasi yaitu suatu kompilasi kekuatan tenaga yang bersumber daridalam maupun luar individu yang melalui sikap dan memutuskan bentuk, arah, dan instensitas (Usmara 2006). Hodgetts dan Luthans mengatakan bahwa motivasi sebagai proses psikologis melalui kemauan yang belumterpuaskan, yang diarahkan pencapaian yang diarahkan.

Selain pelatihan dan motivasi sebagai penunjang kinerja karyawan,kompensasi juga menjadi salah satu faktor yang dapat mempengaruhi produktivitaskerja seorang pegawai. PT. SariWarna Asli II Boyolali adalah perusahaan manufaktur tekstil terintegritas terbesar di kabupaten Boyolali. Dengan jumlah karyawannya 2700 karyawan yang terbagi menjadi duagolongan yaitu karyawan tetap, dan karyawan kontrak. Berdasarkan jumlah karyawan diatas 15\% karyawan berstatus kontrak,sehingga masih memerlukan pelatihan dan motivasi untuk membentuk sumber daya manusia yang berkualitas sesuai dengan Visi dan Missi dari perusahaan. Pelatihanyang diberikan perusahaan bertujuan untuk meningkatkan, mengembangkan kompetensi kerja para karyawan, produktivitas, disiplin, etika, dan etos kerja pada tingkat keterampilan dan skill tertentu yang sesuai dengan jenjang dan kualifikasi jabatan/pekerjaan, sehingga semua karyawan bisa menetap dan berkualitas sesuai bidangnya. Individu kaya akan motivasiakan bekerja dengan sungguhsungguh, Secara tidak langsung hal tersebut akan membantu dan mempengaruhi semua orang di dalam untuk semanggat bekerja.

Sehungga dari penjelasan diatas maka penulis melahirkan sebuah judul yaitu "PENGARUH PELATIHAN,MOTIVASI, DAN KOMPENSASI TERHADAP KINERJA KARYAWANPT. SARI WARNA ASLI II, BOYOLALI".

\section{Rumusan masalah}

Rumusan masalah dalam penelitian ini adalah sebagai berikut: Apakah pelatihan, motivasi dan kompensasi berpengaruh secara parsial terhadap kinerja karyawan bagian Spining 2 PT. Sari Warna Asli II Boyolali?. Danapakah pelatihan, motivasi, dan kompensasi berdampak secara simultan kepada kinerja karyawan di bagian Spining 2 PT. Sari warna asli II boyolali.?

\section{Tujuan penelitian}

Secara umum dari penelitian ini mempunyai tujuan yaitu apakah pelatihan, motivasi serta kompensasi berpengaruh secara parsial padakerja karyawan bagian Spining 2 PT Sari Warna Asli II, Boyolali?

\section{Landasan Teori dan Pengembangan Hipotesis}

Simamora mengemukakan pendapatanya bahwa (1995 : 327), kinerja karyawan adalah tingkat terhadap mana para karyawan mencapai persyaratan-persyaratan pekerjaan.

Dalam pendapat yang di kemukakan oleh George R. Terry ia mengatakan bahwa (1997: 5), manajemen merupakan proses yang mempunyai tipikal yang terdiri drai berbagai macam mulai dari kegiatan tidakan perencanaan kemudian mengorganisir, eksekusi dan terakhir harus ada 
pengawasan guna mencapai tujuan dengan pemanfatan sumber daya manusia dan sumber daya yang lain juga.

Simamora dalam Sutrisno menandaskan bahwa (2015:5), dalam ilmu menajemen SDM memiliki pengertian yakni pendayahgunaan kemudian akan di kembangkan lalu ada penilaian dan terakhir pemberian balas jasa pada seorang karyawan organisasi atau ketua kelompok pekerja.

dalam Widodo yang di maksud dengan (2015:82), pelatihan adalah serangkaian aktivitas seseorang dalam mengembangkan keahliannya dan pengetahuan secara sistematis sehingga bisa mempunyai kinerja yang profesional di bidangnya. Pelatihan merupakan proses pembelajaran yang memungkinkan pegawai melakukan pekerjaan yang sekarang sesuai dengan standarnya.

motivasi yaitu proses mempengaruhi serta memberikan sebuah dorongan pada seorang idividu maupun kelompok dalam pekerjaan agar dapat melakukan sesuatu hal di dalam perusahaan yang telah di tetapkan untuk kemajuan perusahaan. Samsudin (2010:281). Beda dengan ungkapan Liang Gie dalam Samsudin ia mengemukakan bahwasannya motivasi merupakan suatu ide yang dihasilkan manajer yakni semanggat ispirasi dan dorongan sehingga kemudian karyawanya mengikuti maka akan melahirkan tindakan tertentu melalui ide tresebut.

Sedarmayanti mengatakan bahwa (2011:239), pengertian kompensasi adalah segala sesuatu yang di terima oleh karyawan sebagai balas jasa kerja mereka.

Disini kesimpulan sementara dari hipotesis adalah: H1:Pelatihan, motivasi dan kompensasi dapat berpengaruh secara parsial terhadap kinerja karyawan bagian Spining 2 Pt. Sari Warna Asli II,Boyolali $\mathrm{H}_{0}$ : pelatihan, motivasi serta kompensasi berdampak secara simultan kepada kinerja karyawan.

\section{Metode Penelitian}

Penelitian ini adalah penelitian kuantitatif, teknik pengumpulan data yang digunakan adalah Angket (Kuesioner) dan studi dokumen, populasi yang digunakan merupakan 635 karyawan bagian Spining 2 PT. Sari Warna Asli II, Boyolalidan sampel penelitian setelah digunakan hitung Slovin ditemukan hasil sebesar 250 karyawan sebagai responden, obyek penelitian merupakan karyawanbagian Spining 2 PT. Sari Warna Asli II, Boyolali

Definisi variable pelatihan (X1) yang di terapkan di PT. Sari Warna Asli II Boyolali adalah pelatihan yang diadakan setiap tahun untuk meningkatkan wawasan dan keahlian karyawan serta untuk promosi jabatan.

Pada pemberian motivasi (X2) yang di terapkan PT. Sari Warna Asli II Boyolali, setiap kurang 15 menit jam kerja dimulai, dilakukan pengarahan, motivasi dan do'a bersama yang di pimpin langsung oleh kepala bagian Spining 2 PT. Sari Warna Asli II, Boyolali. Karena motivasi akan membuat individu berusaha sekuat tenaga untuk mencapai yang diinginkannya.

Pemberian kompensasi (X3) yang di terapkan diPT. Sari Warna Asli II Boyolali yaitu pemberian kompensasi prestasi, di berikannya uang prestasi itu karena karyawan tersebut mempunyai keahlian untuk menunjang produksi dan mampu melebihi yang ditargetkan. Pemberian kompensasi diPT. Sari Warna Asli II Boyolali.

Kinerja karyawan PT. Sari Warna Asli II Boyolalimenerapkan penilaian atas produktivitas karyawan dengan melihat hasil kerja karyawan, pencapaian kerja, peningkatan penguasaan pekerjaan di masing-masing divisi, respon inisiatif dan kreativitas karyawan, kerja sama antar karyawan dan antar divisi dalam bekerja. Metode analisis data dalam penelitian ini dengan analisis regresi berganda yakni untuk mengukur hubungan antara variabel dependen dan variabel independen. 


\section{Hasil Dan Pembahasan}

\section{Analisis Data}

\section{i. Analisis Deskriptif}

Pada riset ini dan pengambilan data di lakukan selama 2 (dua) pekan dan mendaptkan jumlah responden sebanyak 250 responden pada karyawan yang ada dibagian spinning 2 di Pt sari wali asli II Boyolali.

\begin{tabular}{|l|l|}
\hline Usia & $\begin{array}{c}\text { Karyawan bagian } \\
\text { spinning 2 pt sari } \\
\text { warnaasli II boyolali }\end{array}$ \\
\hline $18-28$ & 120 \\
\hline $29-39$ & 90 \\
\hline $40-50$ & 40 \\
\hline \multicolumn{2}{|c|}{ Sumber primer, diolah tahun 2020} \\
\hline
\end{tabular}

Tabel 4.1

Karakteristik responden menurut umur karyawan bagian spining 2 PT. Sari Warna Asli II Boyolali.

Berdasarkan tabel diatas dapat berikan penjelasan bahwa dari jumlah 250 responden dalam penelitian ini terdapat 120 responden yang berumur 18-28 tahun, 90 responden berumur 29-39tahun dan responden 40 berumur 40-50 tahun.

\subsubsection{Hasil Penelitian Karakteristik Responden Berdasarkan Jenis Kelamin}

Merupakan deskripsi dari karakteristik responden berdasarkan dari jenis kelamin karyawan bagian Spinning 2 PT. Sari Warna Asli II Boyolali, terlihat pada tabel 4.2 sebagai berikut :

Tabel 4.2

Berdasarkan Jenis Kelamin

\begin{tabular}{|l|l|l|}
\hline Jenis Kelamin & Jumlah & Prosentase ( \% ) \\
\hline Laki-laki & 70 & $28 \%$ \\
\hline Perempuan & 180 & $72 \%$ \\
\hline Jumlah & $\mathbf{2 5 0}$ & $\mathbf{1 0 0 \%}$ \\
\hline
\end{tabular}

Sumber : Data Primer diolah, 2020

Dari Tabel 4.2 diatas diketahui bahwa jumlah 250 karyawan bagian Spining 2 PT. Sari Warna Asli II, Boyolali yang dijadikan sebagaiinforman paling banyak yaitu mereka yang memiliki jenis kelamin perempuan sebanyak 180responden atau $72 \%$ sedangkan sisanya sebanyak 70responden dengan presentase $28 \%$ yaitu mereka yang memiliki berjenis kelamin laki-laki. Hal ini menunjukkan bahwa karyawan pada perusahaan tersebut dikuasai oleh karyawan perempuan.

\section{Uji Instrumen Penelitian}

\subsubsection{Uji Validitas}

Dalam riset yang dilakukan oleh penulis di bagian Spining 2 PT. Sari Warna Asli II Boyolali, pengumpulan data dikerjakan dengan menarik responden secara perhitungan rumus Slovin sebanyak 250 informan. Uji validitas ini bertujuan agar dapat menggetahui apakah dalam setiap butir kuesioneryang diajukan untuk 
responden tlah sah atau tidak valiid. Uraian hasil pengujian validitas instrumen dapat dijelaskan dalam bentuk tabel sebagai berikut :

\subsubsection{Validitas item pertanyaan untuk variabel Pelatihan \\ Tabel 4.4 \\ Variabel Pelatihan ( X1 )}

\begin{tabular}{|l|l|l|l|l|}
\hline Variabel & Pernyataan & $\mathbf{r}_{\text {hitung }}$ & $\mathbf{r}_{\text {tabel }}$ & $\begin{array}{l}\text { Keteranga } \\
\mathbf{n}\end{array}$ \\
\hline \multirow{5}{*}{ Pelatihan $\left(\mathrm{X}_{1}\right)$} & Butir 1 & 0,424 & 0,104 & Valid \\
& Butir 2 & 0,527 & 0,104 & Valid \\
& Butir 3 & 0,473 & 0,104 & Valid \\
& Butir 4 & 0,465 & 0,104 & Valid \\
& Butir 5 & 0,395 & 0,104 & Valid \\
& Butir 6 & 0,434 & 0,104 & Valid \\
& Butir 7 & 0,506 & 0,104 & Valid \\
\hline
\end{tabular}

SumberSumber : Data Primer diolah, 2020

Dengan melihat table. 4.4 diatas menunjukkan bahwasanyaaitem pernyataan variabel pelatihan semua dinyatakan valid, karena $\mathrm{r}_{\text {hitungl }}>\mathrm{r}_{\text {tabel. }}$. Skor tertinggi sebesar 0,527>0,104 menandakan bahwa butir 2 tersebut adalah indikator yang dominan membentuk respon terhadap variabel pelatihan yaitu "Pelatihan dapat meningkatkan partisipasi dalam volume pekerjaan untuk mengejar target" .

\subsubsection{Validitas item pertanyaan untuk variabel Motivasi}

Tabel 4.5

Variabel Motivasi ( X2 )

\begin{tabular}{|l|l|l|l|l|}
\hline Variabel & Pernyataan & $\mathbf{r}_{\text {hitung }}$ & $\mathbf{r}_{\text {tabel }}$ & Keterangan \\
\hline \multirow{4}{*}{ Motivasi $\left(\mathrm{X}_{2}\right)$} & Butir 8 & 0,487 & 0,104 & Valid \\
& Butir 9 & 0,670 & 0,104 & Valid \\
& Butir 10 & 0,626 & 0,104 & Valid \\
& Butir 11 & 0,503 & 0,104 & Valid \\
& Butir 12 & 0,758 & 0,104 & Valid \\
& Butir 13 & 0,640 & 0,104 & Valid \\
& Butir 14 & 0,736 & 0,104 & Valid \\
\hline
\end{tabular}

sumber : data primer diolah, 2020

Dengan memeriksa diatas mengindikasikan bahwasanya item-item penjelasan variabel motivasi semua dikatakan sah, karena $r_{\text {hitung }}>r_{\text {tabel. }}$. Skor tertinggi sebesar 0,758>0,104 mengisyaratkan bahwa butir 12 tersebut adalah indikator yang dominan membentuk respon terhadap variabel motivasi yaitu "keselamatan kerja di jamin oleh perusahaan". 


\subsubsection{Validitas item pertanyaan untuk variabel Kompensasi}

Tabel 4.6Variabel kompensasi (X3)

\begin{tabular}{|l|l|l|l|l|}
\hline Variabel & Pernyataan & $\mathbf{r}_{\text {hitung. }}$ & $\mathbf{r}_{\text {tabel. }}$ & Keterangan \\
\hline \multirow{4}{*}{ Kompensasi $\left(\mathrm{X}_{3}\right)$} & Butir 15 & 0,349 & 0,104 & Valid \\
& Butir 16 & 0,439 & 0,104 & Valid \\
& Butir 17 & 0,396 & 0,104 & Valid \\
& Butir 18 & 0,451 & 0,104 & Valid \\
& Butir 19 & 0,409 & 0,104 & Valid \\
& Butir 20 & 0,447 & 0,104 & Valid \\
& Butir 21 & 0,476 & 0,104 & Valid \\
\hline
\end{tabular}

Sumber : Data Primer diolah, 2020

Dengan melihat Tabel 4.6 diatas mengindikasikan bahwa item-item pernyataan dalam variabel kompensasi semua dinyatakan valid, karena $\mathrm{r}_{\text {hitung }}>\mathrm{r}_{\text {tabel. }}$. Skor tertinggi sebesar 0,476>0,104 menandakan bahwa butir 21 tersebut adalah indikator yang dominan membentuk respon terhadap variabel kompensasi yaitu "besarnya jaminan kecelakaan kerja sudah sesuai dengan resiko pekerjaan".

\subsubsection{Validitas item pertanyaan untuk variabel Kinerja Karyawan}

Tabel 4.7Variabel Kinerja Karyawan( Y )

\begin{tabular}{|l|l|l|l|l|}
\hline Variabel & Pernyataan & $\mathbf{r}_{\text {hiitung }}$ & $\mathbf{r}_{\text {tabell }}$ & Keterangan \\
\hline \multirow{5}{*}{ Kinerja Karyawan (Y) } & Butir 22 & 0,535 & 0,104 & Valid \\
& Butir 23 & 0,510 & 0,104 & Valid \\
& Butir 24 & 0,423 & 0,104 & Valid \\
& Butir 25 & 0,602 & 0,104 & Valid \\
& Butir 26 & 0,464 & 0,104 & Valid \\
& Butir 27 & 0,474 & 0,104 & Valid \\
& Butir 28 & 0,750 & 0,104 & Valid \\
\hline
\end{tabular}

Sumber : Data Primer diolah, 2020

Dengan melihat tabel 4.7 diatas mengindikasikan bahwasannya item-item pernyataan variabel kinerjaa karyawan semua dinyatakan valid, karena $r_{\text {hitung }}>r_{\text {tabel. }}$ Skor tertinggi sebesar 0,750>0,104 menandakan bahwa butir 28 tersebut adalah indikator yang dominan membentuk respon terhadap kinerja karyawan yaitu "Saya selalu menerapkan prosedur yang di terapkan di perusahaan"

\subsubsection{Uji Reliabilitas}

Uji reliabilitas diartikan sebagai pengujian sejauh mana hasil sebuah pengukuran dapat di percaya jika menggunakan sebuah computer dengan program SPSS 22, maka nilai alpha akan di muat sebagai berikut :

suatu pengukuran bisa dipercaya, dengan memakai alat bantu komputer pada program SPSS 22 maka dapat nilai alpha dalam bentuk seperti table sbb : 
Tabel 4.8

Hasil uji Reabilitas

\begin{tabular}{|l|l|l|l|}
\hline \multicolumn{1}{|c|}{ Variabel } & $\begin{array}{c}\text { Cronbach'a } \\
\text { Alpha }\end{array}$ & \multicolumn{1}{c|}{$\mathrm{r}_{\text {tabell }}$} & Keterangan \\
\hline Pelatihan $\left(\mathrm{X}_{1}\right)$ & 0,378 & 0,104 & Reliabel \\
Motivasi $\left(\mathrm{X}_{2}\right)$ & 0,751 & 0,104 & Reliabel \\
Kompensasi $\left(\mathrm{X}_{3}\right)$ & 0,247 & 0,104 & Reliabel \\
Kinerja Karyawan $(\mathrm{Y})$ & 0,599 & 0,104 & Reliabel \\
\hline
\end{tabular}

Sumber: Data Primer diolah, 2020

Dengan melihat hasil diatas diketahui bahwa item pernyataan dari variabel pelatihan dengan nilai Cronbach'a Alpha 0.378 dalam penelitian ini adalah reliabel, variabel motivasi dengan nilai Cronbach'a Alpha motivasi dengan nilai Cronbach'a Alpha 0.751 dalam penelitian ini adalah reliabel, variable kompensasi dengan nilai Cronbach'a Alpha kompensasi 0.247 dalam penelitian ini adalah reliabel, dan variable kinerja karyawan dengan nilai Cronbach'a Alpha motivasi dengan nilai Cronbach Alpha 0.599 dalam penelitian ini adalah reliabel. Hal tersebut ditunjukan

\section{Analisis Data} oleh nilair $_{\text {tabel }}>0,104$. Sehingga kuesioner di buat untuk mendukung penelltian ini. hipotesis.

Pengujian persyaratan analisis data dipergunakan sebelum melakukan pengujian

\subsubsection{Uji Asumsi Klasik}

1. Uji Normalitas

Uji normalitas data akan menjadi persyaratan penting dalam penguraian parametik, seperti regresi dan anova. Pada Uji normalitas ini agar mengetahui dalam model reggresi, variabel residual mempunyai distribusi normal. Namun Jika asumsi demikian dilanggar, apakah uji statistik akan berubah menjadi tidak valid atau bisa, terutama padarepresentatifnya kecil.

Tabel 4.9

Uji Normalitas

\section{One-Sample Kolmogorov-Smirnov Test}

\begin{tabular}{|lll|l|}
\hline & & $\begin{array}{l}\text { Unstandardize } \\
\text { d Residual }\end{array}$ \\
\hline N & & 250 \\
Normal Parameters & & Mean &, 0000000 \\
& & Std. Deviation & 2,24054552 \\
Most & Extreme & Absolute &, 057 \\
Differences & & Positive &, 029 \\
& & Negative &,- 057 \\
Test Statistic & & &, 057 \\
Asymp. Sig. (2-tailed) & &, $645^{\mathrm{c}}$ \\
\hline
\end{tabular}



a. Test distribution is Normal.
b. Calculated from data.
c. Lilliefors Significance Correction.

Sumber ; data yang di olah 2020.

Berdasarkan tabel 4.9 diatas kita bisa mengetahui pernyataan dari vhariabel pelatihan, motivasi dankompensasi kerja dalam riset ini adalah berdistribusi normal. Hal tersebut ditunjukan oleh nilai sig masing masing variabel $0,645>0,05$.

\section{Uji Multikolinearitas}

Dalam pengujian ini bermaksud agar dapat mencoba mengetahui bahawa apakah dalam pengujian ini terdapat hubungan pada model regresi di dalam variabel bebas dan independen. Jika di dalam regresi anatara vhariabel independent dan bebas terdapat hubungan tidak baik maka akan memungkinkan model regresi akan berprose baik. Sehinggah penelitian ini pada ujimultikolinearitas dilihat berdasarkan bentuk nilai tolerance dan variance inflation factor (VIF).

Tabel 4.10

UjiMultikolinearitas

\begin{tabular}{|c|c|c|c|c|c|c|}
\hline \multirow{2}{*}{\multicolumn{2}{|c|}{ Model }} & \multicolumn{2}{|c|}{ Unstandardized Coefficients } & \multirow{2}{*}{$\begin{array}{l}\text { Standardized } \\
\text { Coefficients } \\
\text { Beta }\end{array}$} & \multicolumn{2}{|c|}{ Collinearity Statistics } \\
\hline & & B & Std. Error & & Tolerance & VIF \\
\hline \multirow[t]{4}{*}{1} & (Constant) & 17,932 & 3,240 & & & \\
\hline & PELATIHAN &, 031 &, 068 &, 029 &, 970 & 1,031 \\
\hline & MOTIVASI &, 052 &, 049 &, 067 &, 971 & 1,030 \\
\hline & $\begin{array}{l}\text { KOMPENSAS } \\
\text { I }\end{array}$ &, 267 &, 076 &, 219 & ,997 & 1,003 \\
\hline
\end{tabular}

Sumber : Data yang diolah, 2020

Berdasarkan penjelasan diatas kita bisa menyimpulkan bahwa terjadinya multiikolinearitas, dari hasil perhitungaan koefisien model regresi didapatkan bahwasannya valuetolerance lebih dari 0,1 sedangkan untuk nilai VIFnya kurang dari 10. Sehinggah bisan di Tarik kesumpulan pada model regresi pada variable bebas tidak ada multikolinearitas.

\section{UjiHeterokedastisitas}

Dalam uji multiikolinearitasingin di cari apa ada kejadiaan ketidaksepadaan varian dari residual pada penglihatan satu dengan yang lainya di dalam model regresi. Multikolinearitasaka muncul jika di dalam varian dan residual satu pengamatan. Sehinggah untu menciptakan model regresi yang lebig baik iyalah jika tidak terjadinya multikolinearitas. 
Tabel 4.11

Uji Heterokedastisitas

\section{Coefficients $^{\mathbf{a}}$}

\begin{tabular}{|c|c|c|c|c|c|c|}
\hline \multirow{2}{*}{\multicolumn{2}{|c|}{ Model }} & \multicolumn{2}{|c|}{ Unstandardized Coefficients } & \multirow{2}{*}{\begin{tabular}{|l|}
$\begin{array}{l}\text { Standardized } \\
\text { Coefficients }\end{array}$ \\
Beta
\end{tabular}} & \multirow[b]{2}{*}{$\mathrm{t}$} & \multirow[b]{2}{*}{ Sig. } \\
\hline & & B & Std. Error & & & \\
\hline \multirow[t]{4}{*}{1} & (Constant) &, 145 & 1,959 & & ,074 &, 941 \\
\hline & PELATIHAN &, 051 &, 041 &, 080 & 1,238 &, 037 \\
\hline & MOTIVASI &,- 015 &, 029 &,- 032 &,- 498 &, 619 \\
\hline & $\begin{array}{l}\text { KOMPENSAS } \\
\text { I }\end{array}$ &, 018 &, 046 &, 025 & ,398 & ,471 \\
\hline
\end{tabular}

a. Dependent Variable: ABS_RES

Sumber : Data yang diolah, 2020

Hasil tampilan output SPSS 22 menunjukkan koefisien untuk variabel pelatihan variabel motivasi dan variabel kompensasi mempunyai nilai signifikansi $0,941>0.05$ bisa di simpulkan tidak terdapat gejala heterokedastisitas.

\section{Uji Autokorelasi}

Pada model regresi linear aka nada namanya pengujian autokorelasi yang mana di gunakan untuk mengetahui adanya singgungan kesalahan pada pengganggu $t$ terhdap kesalahan penggangu periode t-1. Jika di temukan adanya singgungan maka akan di namakakn masalah autokorelasi.

Tabel 4.12

\section{ModelSummary ${ }^{\text {b. }}$}

\begin{tabular}{|l|l|l|l|l|l|}
\hline Model & $\mathrm{R}$ & $\mathrm{R}$ Square & $\begin{array}{l}\text { Adjusted R } \\
\text { Square }\end{array}$ & $\begin{array}{l}\text { Std. Error of } \\
\text { the Estimate }\end{array}$ & $\begin{array}{l}\text { Durbin- } \\
\text { Watson }\end{array}$ \\
\hline 1 &, $229^{\mathrm{a}}$ &, 052 &, 041 & 2,254 & 1,952 \\
\hline
\end{tabular}

a. predictors: (Constant), Kompensasi, Motivasi, Pelatihan

b. dependent Variable: KINERJA

Sumber : data yang diolah 2020

Dari hasil semua analisis output SPSS 22 Tabel4.12 diatas menunjukkan besarnya nilai Durbin Watson sebesar 1,952. Dengan jumlah 
variabel independen tiga $(\mathrm{k}=3)$ dan jumlah sampel $250(\mathrm{n}=250)$ diperoleh nilai dl sebesar 1,776 dan dusebesar 1,808. Oleh karena nilai DW hitung 1,952> du 1,808 dan dengan menggunakan nilai signifikan 5\%, maka dapat disimpulkan tidak terjadi autokorelasi antar residual.

\subsubsection{Analisis Regresi}

\subsubsection{Analisis Regresi Berganda}

Analisis Regresi Berganda ini dilakukan agar bisa mengetahui bagaimana pengaruh antara variabel pelatihan $X_{1}$, motivasi $X_{2}$ dan kompensasi $\mathrm{X}_{3}$ terhadap variabel kinerja karyawan $\mathrm{Y}$. Berdasarkan pada hasil perhitungan diketahui persamaan garis regresi seperti pada table di bawah ini sebagai berikut :

Tabel 4.13Output Regresi Linier Berganda

\section{Coefficients $^{\mathrm{a}}$}

\begin{tabular}{|c|c|c|c|c|c|c|}
\hline \multirow{2}{*}{\multicolumn{2}{|c|}{ Model }} & \multicolumn{2}{|c|}{ Unstandardized Coefficients } & \multirow{2}{*}{\begin{tabular}{|l}
$\begin{array}{l}\text { Standardized } \\
\text { Coefficients }\end{array}$ \\
Beta
\end{tabular}} & \multirow[b]{2}{*}{$\mathrm{t}$} & \multirow[b]{2}{*}{ Sig. } \\
\hline & & B & Std. Error & & & \\
\hline \multirow[t]{2}{*}{1} & $\begin{array}{l}\text { (Constant) } \\
\text { PELATIHAN }\end{array}$ & $\begin{array}{l}3.438 \\
.359\end{array}$ & $\begin{array}{l}2.092 \\
.089\end{array}$ & .389 & $\begin{array}{l}1.643 \\
4.039\end{array}$ & $\begin{array}{l}.104 \\
.000\end{array}$ \\
\hline & $\begin{array}{l}\text { MOTIVASI } \\
\text { KOMPENSAS } \\
\text { I }\end{array}$ & $\begin{array}{l}.243 \\
.217\end{array}$ & $\begin{array}{l}.099 \\
.097\end{array}$ & $\begin{array}{l}.234 \\
.193\end{array}$ & $\begin{array}{l}2.452 \\
2.242\end{array}$ & $\begin{array}{l}.016 \\
.027\end{array}$ \\
\hline
\end{tabular}

a. Dependent Variable: KINERJA

Sumber : Data yang diolah, 2020

Persamaan regresi yang diperoleh dari perhitungan tersebut adalah sebagai sbb :

$$
\begin{aligned}
& Y=\alpha+b_{1} \cdot X_{1}+b_{2} \cdot X_{2}+b_{3} \cdot X_{3}+e \\
& Y=3.438+0.359 X_{1}+0.243 X_{2}+0.217 X_{3}+e
\end{aligned}
$$

Dimana :

$$
\begin{array}{ll}
\mathrm{Y} & =\text { Kinerja Karyawan } \\
\mathrm{A} & =\text { Nilai Konstanta } \\
\mathrm{X}_{1} & =\text { Variabel Pelatihan } \\
\mathrm{X}_{2} & =\text { Variabel Motivasi } \\
\mathrm{X}_{3} & =\text { Variabel Kompensasi }
\end{array}
$$




$$
\begin{array}{ll}
\mathrm{Y} & =\text { Kinerja Karyawan } \\
\mathrm{E} & =\text { error term (diabaikan) }
\end{array}
$$

Semua kesamaan diatas, bisa di jelaskan besar konstanta 3.438 mengindikasikan bahwa jika tidak ada variabel pelatihan $\left(\mathrm{X}_{1}\right)$, variabel motivasi $\left(\mathrm{X}_{2}\right)$ dan variabel kompensasi $\left(\mathrm{X}_{3}\right)$ maka nilai kinerja karyawan sebesar 3.438 satuan. Dari pernyataan diatas maka dapat disimpulkan bahwa model regresi cocok dipakai untuk memprediksi kinerja karyawan, dimana :

\begin{tabular}{|c|l|}
\hline$\alpha=3.438$ & $\begin{array}{l}\text { Koefisien regresi pelatihan, motivasi dan } \\
\text { kompensasihasilnya }=0, \text { maka nilai kinerja } \\
\text { karyawan seebesar 3.438 satuan. }\end{array}$ \\
\hline $\mathrm{X}_{1}=$ & $\begin{array}{l}\text { Koefisien regresi pelatihan sebesar } 0.359 \text { berarti } \\
\text { setiap terjadi kenaikan, nilai pelatihan }\left(\mathrm{X}_{1}\right) \text {, maka } \\
\text { akan menaikkan nilai kinerja karyawan (Y) } \\
\text { sebesar 0.359. }\end{array}$ \\
\hline $\mathrm{X}_{2}=$ & $\begin{array}{l}\text { Koefisien regresi motivasi sebesar 0.243 berarti } \\
\text { setiap terjadi kenaikan, nilai motivasi }\left(\mathrm{X}_{2}\right), \text { maka } \\
0.243 \\
\text { akan menaikkan nilai kinerja karyawan (Y) } \\
\text { sebesar 0.243. }\end{array}$ \\
\hline $\mathrm{X}_{3}=$ & $\begin{array}{l}\text { Koefisien regresi kompensasi sebesar 0.217 } \\
\text { berarti setiap terjadi kenaikan, nilai kompensasi } \\
\left(\mathrm{X}_{3}\right), \text { maka akan menaikkan nilai kinerja karyawan } \\
(\mathrm{Y}) \text { sebesar 0.217. }\end{array}$ \\
&
\end{tabular}

\section{Pengujian Hipotesis}

\subsubsection{Uji t}

Tujuan penelitian ini agartmengetahui hubungan yang signifikan dari masingmasing bentu variabel independen pada variabel dependen, apakah pelatihan $\mathrm{X}_{1}$, motivasi $\mathrm{X}_{2}$ dan kompensasi $\mathrm{X}_{3}$ dengan cara persial dapat mempengaruhi kinerja karyawan yakni dengan caraakan membandingkan $\mathbf{r}_{\text {hitung }}$ dengan $\mathbf{r}_{\text {tabel }}$ dengan taraf signifikan 0,05 atau $5 \%$.

Uji t di gunakan agar menyurvei lebih lanjut di manakah antara ketiga variabel independen yang terlihat menonjol pada pekerja karyawan.. dengan demikian hasil risetvariabel Independen yang dimasukkan pada model tersebut dengan nilai signifikan 5\% dapat disimpulkan variabel pelatihanmotivasi kompensasi tidak berpengaruh signifikan terhadap kinerja karyawan karena bernilai $>0,05$. Sedangkan variabel pelatihan berpengaruh signifikan terhadap kinerja karyawan karena bernilai $<0,05$.

Perumusan Hipotesis :

$H_{0}$ : variabel pelatihan $X_{1}$, motivasi $X_{2}$ dan kompensasi $X_{3}$ secara parsial tidak berpengaruh terhadap kinerja karyawan.

$H_{a}$ : variabel pelatihan $X_{1}$, motivasi $X_{2}$, dan kompensasi $X_{3}$, secara parsialsangat memengaruhi kerja karyawan. 
Tabel. 4.14

Tabel Uji t

\section{Coefficients $^{\mathrm{a} \cdot}$}

\begin{tabular}{|c|c|c|c|c|c|c|}
\hline \multirow{2}{*}{\multicolumn{2}{|c|}{ Model }} & \multicolumn{2}{|c|}{ Unstandardized Coefficients } & \multirow{2}{*}{\begin{tabular}{|l}
$\begin{array}{l}\text { Standardized } \\
\text { Coefficients }\end{array}$ \\
Beta
\end{tabular}} & \multirow[b]{2}{*}{$\mathrm{t}$} & \multirow[b]{2}{*}{ Sig. } \\
\hline & & B & Std. Error & & & \\
\hline \multirow[t]{2}{*}{1} & $\begin{array}{l}\text { (Constant) } \\
\text { PELATIHAN }\end{array}$ & $\begin{array}{l}3.438 \\
.359\end{array}$ & $\begin{array}{l}2.092 \\
.089\end{array}$ & .389 & $\begin{array}{l}1.643 \\
4.039\end{array}$ & $\begin{array}{l}.104 \\
.000\end{array}$ \\
\hline & $\begin{array}{l}\text { MOTIVASI } \\
\text { KOMPENSAS } \\
\text { I }\end{array}$ & $\begin{array}{l}.243 \\
.217\end{array}$ & $\begin{array}{l}.099 \\
.097\end{array}$ & $\begin{array}{l}.234 \\
.193\end{array}$ & $\begin{array}{l}2.452 \\
2.242\end{array}$ & $\begin{array}{l}.016 \\
.027\end{array}$ \\
\hline
\end{tabular}

a. dependen variable : Kinerja

Sumber : Data yang diolah, 2020

Tabel 4.15

Hasil Uji t

\begin{tabular}{|l|l|l|l|}
\hline Variabel & $\mathbf{t}$ & Sig & Keterangan \\
\hline Pelatihan & 1.238 & 0,000 & Signifikan \\
\hline Motivasi & -.498 & 0,016 & Signifikan \\
\hline Kompensasi & 398 & 0,027 & Signifikan \\
\hline
\end{tabular}

Sumber : Data yang diolah, 2020

\section{Pembahasan :}

1. Analisis terhadap variabel pelatihan

Untuk variabel pelatihan, apabila Sig. $0,00<0,05$ maaka $\mathrm{H}_{\mathrm{o}}$ diteriima sedangkan $\mathrm{H}_{\mathrm{a}}$ ditolak. nilai Sig. 0.000 ini menunjukkan variabel pelatihan memiliki pengaruh signifikan terhadap kinerja karyawan.

2. Analisis terhadap variabel motivasi

Untuk variabel motivasi, apabila Sig. $0,00<0,05$ maka $\mathrm{H}_{\mathrm{o}}$ diterima dan $\mathrm{H}_{\mathrm{a}}$ ditolak. Nilaii Sig. 0.016 hal ini menunjukkan bahwa variabel motivasi secara 
parsial berpengaruh terhadap kinerja karyawan, dengan kata lain variabel motivasi mempunyai pengaruh signifikan terhadap kinerja karyawan.

3. Analisis terhadap variabel kompensasi

Untuk variabel kompensasi, apabila Sig. 0,00 $<0,05$ maka $H_{o}$ diterima $H_{a}$ ditolak. Nilai Sig. 0.027 hal ini mengisyaratkan bahwa variabel kompensasi secara parsial mempengaruh terhadap kinerja karyawan, dengan kata lain variabel kompensasi mempunyai pengaruh signifikan terhadap kinerja karyawan.

\subsubsection{Uji F}

Pengujian ini bertujuan untuk mengetahui apakah variabel pelatihan $X_{1}$, motivasi $\mathrm{X}_{2}$ dan kompensasi $\mathrm{X}_{3}$ secara berbarengan atau bersama-sama dapat mempengaruhi terhadap kinerja karyawan yaitu dengan membandingkan $\mathrm{F}_{\text {hitung }}$ dengan $\mathrm{F}_{\text {tabel }}$ dengan taraf pada signifikan0,05 atau $5 \% . \mathrm{F}_{\text {tabel }}$ sehinggah di temukan 0,104 berdasarkan tabel $\mathrm{r}$ product moment pada sig. 0,05 (two tail).

Perumusan Hipotesis :

$H_{0}$ : variabel pelatihan $X_{1}$, motivasi $X_{2}$, dan kompensasi $X_{3}$, secara simultan tidak berpengaruh terhadap kinerja karyawan.

$\mathrm{H}_{\mathrm{a}}$ : variabel pelatiihan $\mathrm{X}_{1}$, motivasi $\mathrm{X}_{2}$ dengan kompensasi $\mathrm{X}_{3}$ secara simultan sangat mempengaruhikerja karyawan.

Adapun hasil hitung yang di peroleh menggunakan program computer SPSS 22, yaitu sebagai berikut :

Tabel 4.16

\section{Hasil Uji F}

\section{TABEL ANOVA ${ }^{\mathrm{a}}$}

\begin{tabular}{|cc|c|c|c|c|c|}
\hline \multicolumn{2}{|c|}{ Model. } & $\begin{array}{c}\text { Sum. of } \\
\text { Squares }\end{array}$ & df & Mean Square & F & Sig. \\
\hline $1 \quad$ Regression & 181.537 & 3 & 60.512 & 26.906 & $.000^{\mathrm{b}}$ \\
& Residual & 215.903 & 246 & 2.249 & & \\
& Total & 397.440 & 249 & & & \\
\hline
\end{tabular}

a. Dependent Variable: KINERJA

b. Predictors: (Constant),

Sumber : Data yang diolah, 2020

Dari hasil pengujian ini pada tabel 4.16, bahwa Sig. 0,000 $<0,05$ hal ini menunjukkan bahwa semua variabel berpengaruh secara simultan. Dengan menggunakaan tiingkat $\alpha$ ( alfa )0,05 atau 5\% pada $\mathrm{H}_{\mathrm{o}}$ ditolak dan $\mathrm{H}_{\mathrm{a}}$ gagal ditolak. Penolakan $\mathrm{H}_{\mathrm{o}}$ dibuktikan dengan hasiil perhitunggan dengan nilai Sig. $(0,000)<$ dari $\alpha($ alfa $)=0,05$ sehingga semua bentuk variabel dengansimultandapat mempengaruhi kerja karyawan pada spinning 2 PT. Sari Warna Asli II Boyolali. 


\subsubsection{Uji Koefisien Determinasi}

Pada kondisi koefisien determinasi kita dapat menguji dengan model regresi yakni seberapa jumlah besar pengaruh pada variable indeppenden pada variable deppenden.

\section{Tabel 4.17 Hasil Ujian Koefisien Determinasi}

\section{Summary :}

\begin{tabular}{|l|l|l|l|l|}
\hline Model & $\mathrm{R}$ & R Square & $\begin{array}{l}\text { Adjusted R } \\
\text { Square }\end{array}$ & $\begin{array}{l}\text { Std. Error of } \\
\text { the Estimate }\end{array}$ \\
\hline 1 & $.676^{\mathrm{a}}$ & .457 & .440 & 1.500 \\
\hline
\end{tabular}

a.Predictors:(Constant) kompensasi, motivasi, pelatihan

Sumber : Data yang diolah,2020

Dapat di lihat tabel 4.17 nilai $\mathrm{R}_{\text {Square }}$ sebesar 0.457 , hal ini menunjukkan bahwa variabel pelatihan, motivasi kompensasi secara bersama-sama mampu menjelaskan variabel kinerja karyawan sebesar 45,7\% selebihnya 54,3\% dijelaskan oleh variabel lain seperti gaya kepemimpinan, gaji, lingkungan kerja, jam kerja, pendidikan, dan lain sebagainya.

\section{Kesimpulan}

Setelah melakukan analisis data dan membahas maka bisa di berikan solusi bahwa Karyawan harus mendapatkan pelatihan motivasi dan kompensasi Bagian Spining 2 PT. Sari warna Asli II Boyolali penulis dapat menggambil kesimpulan:

1. Dari regresi bergaanda hasil uji $\mathrm{F}$ secara simultan bahwa nilai signifikasi $0,000<0,05$. Hal ini menunjukan bahwa pelatihan, motivasi, dan kompensasi, berpengaruh signifikan terhadap kinerja karyawan. Sedangkan nilai koefisien determinasi $\left(\mathrm{R}^{2}\right)$ sebesar 0,457 mempunyaidefinisi bahwa pelatihan, motivasi dan kompensasi secara bersama-sama mampu mempengaruhi variabel kinerja Karyawan sebesar 45,7\% selebihnya 55,3\% dipengaruhi oleh variabel lain yang tidak dimasukkan dalam penelitian ini misalnya : gaya kepemimpinan, pendidikan, usia kerja, lingkungan kerja disiplin kerja dan lain sebagainya.

2. Berdasarkan uji $t$ untukk hasilnya menunjukan nilai sig. $0,000<0,05$ berarti pelatihan sangat memmengaruhi pekerjaan karyawan. Berdasarkan hasil analisis regresi berganda dengan Uji t menunjukan niilai sig. $0,016<0,05$ berarti kata motivasi sangat di butuhkan untuk karyawan.Berdasarkan hasilnya regresi berganda dengan uji t menunjukan nilai sig. $0,027<$ 0,05 berarti bahwa kinerja karyawan harus di lihat ternya kompensasi sangat di butuhkan dan berpengaruh pada cara kerja karyawan. 


\section{DAFTAR PUSTAKA}

[1] 'J.K.Penulis', “Judul bab dalam buku,dalam Judul buku, edisi ke-x, Kota Terbit, Negara, tahun, bab x, bagian x, hal. xxx-xxx."

[2] .G.O.Young, "Synthetic structure of industrial plastics dalam Plastics,edisi kedua", vol. 3, "J.Peters,Ed. New York: McGraw-Hill, 1964, hal. 15-64".

[3] “W.K.Chen, Linear Networks and Systems. Belmont,CA:Wadsworth",1993, hal. 123-135'.

[4] "KPenulis, “Judul artikel," Singkatan terbitan berkala”, vol x,bulan, tahun.

[5] "A.Duncombe, "Infrared navigationPart I": ANn assessment" of feasibilit”.. IEEE Trans. Electron Devices", vol. ED-11, no. 1, hal. 34-39, Jan. 1959.

[6] E. P.Wigner, "Theory of traveling-wave optical laser", Phys. Rev., vol. 134, hal. A635-A646, Dec. 1965.

[7] E. H.Miller, “A note on reflector arrays”,IEEE Trans. Antennas Propagat.,

[8] L.R Penulis, “Judul laporan”, Singkatan perusahaan,Kota,Negara,Rep.xxx,tahun”.

[9] E.E.Reber,R.L.Michell,endC.J.Carter, "Oxygen absorption in the earth's atmosphere”, Aerospace Corp., Los Angeles, CA, Tech. Rep. TR-0200 (4230-46)-3, Nov. 1988.

[10] “(J. H.Davis and J. R.Cogdell, "Calibration program for the 16-foot antenna”, Elect. Eng. Res. Lab, Univ.Texas, Austin,Tech.Memo. NGL-006-69-3, Nov. 15, 1987)”. 